Thorax (1961), 16, 99.

\title{
TRAUMATIC DIAPHRAGMATIC HERNIA
}

\author{
BY \\ W. R. PROBERT AND C. HAVARD \\ From Sully Hospital, Glamorgan
}

(RECEIVED FOR PUBLICATION FEBRUARY, 1961)

Rupture of the diaphragm and herniation of the abdominal viscera into the chest are wellrecognized results of crushing or penetrating injuries.

Gordon Bryan's study (1921) of both types of injury is a surgical classic. The second world war rekindled interest in traumatic diaphragmatic hernia, and several important papers dealt with those due to penetrating injury (Edwards, 1943; Mackey and Bingham, 1945; Morgan, 1945). In peacetime reports from the United States (Hughes, Kay, Meade, Hudson, and Johnson, 1948; Bugden, Chu, and Delmonico, 1955; Desforges, Strieder, Lynch, and Madoff, 1957), from Australia (Sutherland, 1958), and from Great Britain (Evans and Simpson, 1950) have drawn attention to the frequency of traumatic diaphragmatic herniae caused by motor accidents where crushing against the steering-wheel was the common mechanism.

In hospitals serving mining and industrial areas traumatic diaphragmatic herniae are more likely to result from falls of coal and rock, or from crushing by trucks and pit cages. They are especially serious because the respiratory function of the injured men is often already impaired by pneumoconiosis and emphysema.

We report 15 cases of traumatic diaphragmatic hernia from a thoracic surgical centre in South Wales. Fourteen were in men whose ages ranged from 16 to 67 years (average 48 years): in four the herniae resulted from penetrating wounds, in 10 from crush injuries. These 10 were coalminers, all but one of whom had been injured at

TABLE I

TRAUMATIC DIAPHRAGMATIC HERNIA

\begin{tabular}{lcccc|c}
\hline Total number & $\ldots$ & $\ldots$ & $\ldots$ & $\ldots$ & 15 \\
Right sided & $\ldots$ & $\ldots$ & $\ldots$ & $\ldots$ & 3 \\
Left , & $\ldots$ & $\ldots$ & $\ldots$ & 12 \\
Due to crushing injury & $\ldots$ & $\ldots$ & $\ldots$ & 11 \\
$\begin{array}{l}\text { Operations performed } \\
\text { Mortality }\end{array}$ & $\ldots$ & $\ldots$ & $\ldots$ & 4 \\
\hline
\end{tabular}

work. The only case seen in a woman was due to a crushing injury in an air-raid. Nine of the 11 herniae due to crushing, and three of the four herniae due to penetrating wounds, were left-sided.

\section{CASE Reports}

CASE 1.-B. M., a coal-miner aged 52 years, had been buried under a fall of rock in 1932 while at work in a kneeling position. He sustained fractures of the third, fourth, and fifth left ribs and a compound fracture of the right leg. He coughed a little blood soon after his injury. Sixteen years later he complained of "wind and rumbling" in the abdomen but had no pain. Chest radiographs (Fig. 1) and barium enema showed the colon to be in the left side of the chest, and a diagnostic pneumoperitoneum produced a pneumothorax.

At left thoracotomy on November 12, 1948, there was a 9 in. tear in the diaphragm extending from the costal margin towards the oesophageal hiatus. A loop of colon had herniated but there was no sac. The gut was reduced and the tear repaired with interrupted thread sutures. Post-operatively the right lower lobe collapsed, but recovery was satisfactory. Four years later he was free from symptoms and radiography showed a sound diaphragm (Fig. 2). In February, 1961, he reported that he was well and working.

CASE 2.-W. R., aged 40 years, was wounded in the left side of the chest in 1943 and nine accessible metal fragments were removed soon afterwards. Six weeks later he developed intestinal obstruction requiring laparotomy and a colostomy which was maintained for three months. In 1950 a left diaphragmatic hernia was recognized and repair was attempted by the abdominal route. His attacks of abdominal pain and vomiting were not relieved thereby, and continued till his admission to Sully Hospital in 1956. Peristalsis could be heard at the base of the left chest, and radiography showed the hernia clearly (Fig. 3). At left thoracotomy on February 17, 1956, the stomach, transverse colon, and omentum were extensively adherent to the lung and the margin of the diaphragmatic tear. The abdominal viscera were reduced and the defect repaired in two layers. His later progress was satisfactory. In February, 1961, he reported that he was well and working as a builder. 

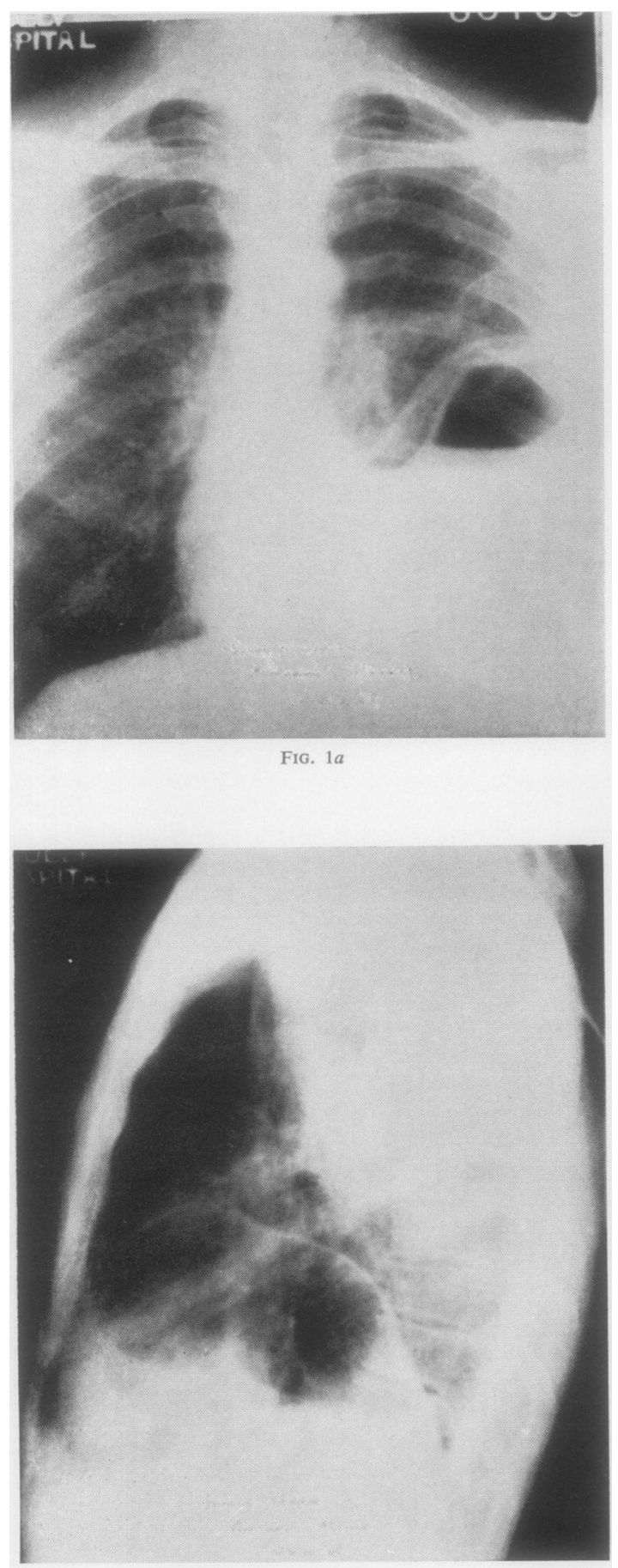

FIG. $1 b$

Fig. $1 a$ and $b$.C Case 1 : Postero-anterior and left lateral radiographs of chest showing herniation of colon through left hemidiaphragm.

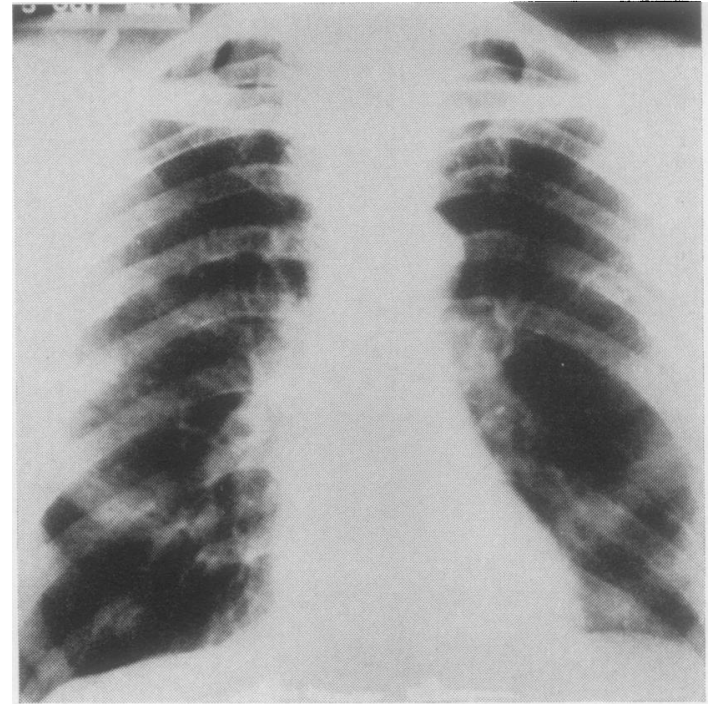

FIG. 2.-Case 1: Postero-anterior radiograph of chest showing state of affairs after repair of the hernia.

Case 3.-W. H., a coal-miner aged 44 years, was gradually crushed beneath a slowly descending pit cage and the bottom of the shaft on December 9, 1956. He was released a few minutes later and immediately complained of pain in the chest, difficulty in breathing, and dimness of vision. He was admitted to hospital soon afterwards. On examination he was grossly dyspnoeic; bowel sounds were heard over the left side of the chest. He showed subconjunctival haemorrhages and petechiae over the upper half of the trunk. Lateral chest radiography, which was difficult owing to his restlessness, showed evidence of bowel herniation anteriorly (Fig. 4). It was not till three days later that he was judged to be fit for left thoracotomy. Lengths of small bowel and part of the transverse colon and omentum entered the chest through a large transverse tear in the front of the diaphragm. On its costal aspect only a narrow rim of peripheral muscle remained. There were several other tears, but they did not involve the full thickness of the diaphragm, the peritoneum remaining intact in each. The lateral portion of the main tear could only be closed by passing sutures round the eighth rib. The medial portion, where the defect extended a little way under the intact pericardium, could only be repaired in one layer. Three weeks later he was in good general condition, the petechiae had disappeared, and his vision had returned to normal. In February, 1961, he was complaining of effort dyspnoea, and had not worked since the accident. Radiology showed the diaphragmatic repair to be sound.

CASE 4.-D. A. S., aged 16 years, sustained an accidental wound of the left chest with a .410 shotgun while out shooting in the country on December 27, 1949. He could hear a gurgling sound from his 


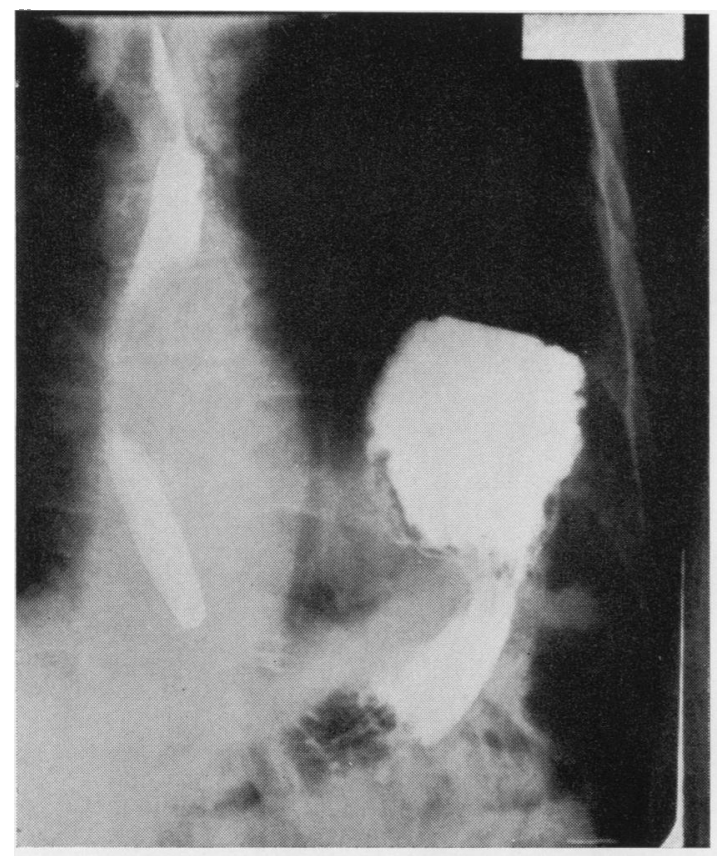

FIG. $3 a$

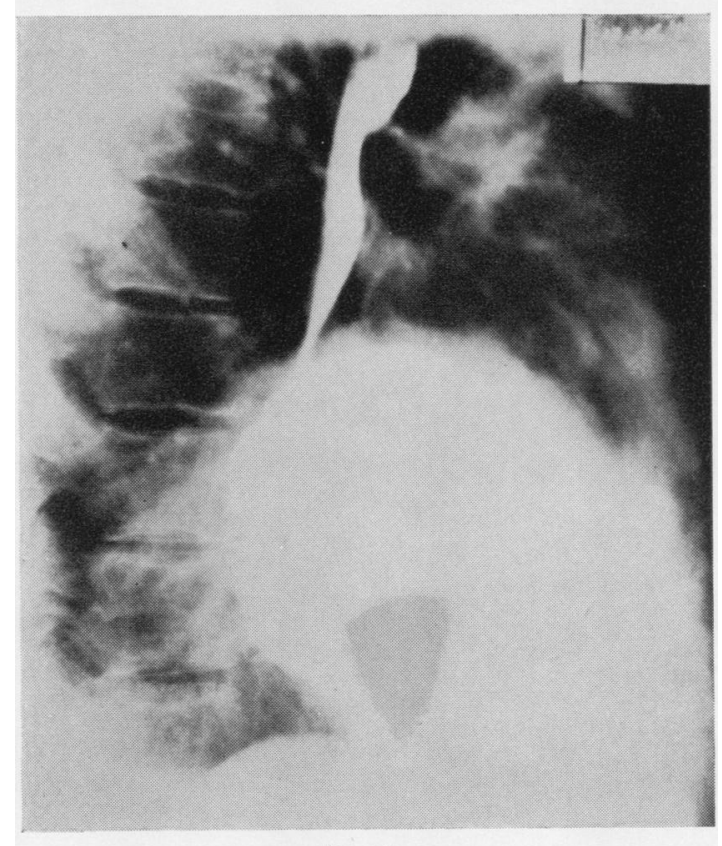

FIG. $3 b$

FIG. $3 a$ and b.-Case 2: Postero-anterior and left lateral chest radiographs after barium swallow showing part of stomach in the left diaphragmatic hernia.

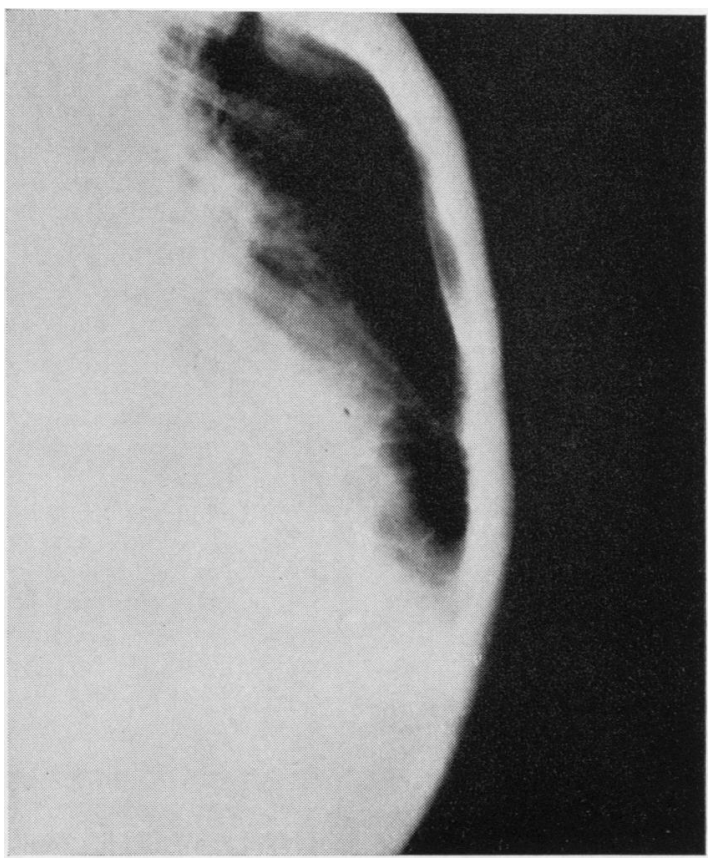

Fig. 4.-Case 3: Left lateral radiograph showing poorly defined pattern of small bowel in the chest.

chest, but managed to run the length of two fields for help, after which he had a brisk haemoptysis. He was taken to Swansea General Hospital, where left anterior thoracotomy was performed. The left lung was found to be lacerated and there was a 4-in. tear in the cupola of the diaphragm. Much blood was aspirated, the diaphragm was sutured, and the chest closed. Laparotomy was then performed, a ruptured spleen removed, a gastric perforation sutured, and a tear of the left lobe of the liver controlled. Postoperative chest aspirations were needed, followed by a period of postural treatment in a right-sided plaster cast before re-expansion of the left lung was achieved. Within eight months he was playing professional football.

In November, 1958, he was working as a painter and decorator, he had no dyspnoea even after vigorous exercise, and had no intestinal symptoms. His chest movements were excellent, all wounds were soundly healed, and radiography showed the left diaphragm to be intact but a little high.

CASE 5.-A. W. M., a coal-miner aged 67 years, was admitted as an emergency with haematemesis and substernal pain. Ever since being crushed by a coal truck six months before, when fractures of the left ninth, tenth, and eleventh ribs had been seen, he had complained of "indigestion pain" behind the sternum. He continued to vomit altered blood for some time after admission. There was dullness to percussion at the base of the left chest. Chest radiography and a barium meal examination showed the greater part of 
the stomach in the left side of the chest. At left thoracotomy on April 14, 1955, un-united rib fractures were seen. The part of the stomach which had herniated was congested but its vessels pulsated. This was returned to the abdomen, and the defect, which lay anteriorly, was sutured. The patient made a good recovery. In February, 1961, he reported that he was well and free from dyspepsia.

CASE 6.-C. W., aged 47 years, had been wounded at Dunkirk in 1940, and a metal fragment had been removed from the left chest wall at an early operation. For 15 years he had suffered from fleeting pains in the abdomen and chest unrelated to food. On investigation in June, 1955, there were no abnormal physical signs. Chest radiography showed an opacity above the left diaphragm; barium meal examination was not helpful, but the presence of a diaphragmatic hernia was confirmed following induction of a pneumoperitoneum (Fig. 5). Operation was refused. In 1956 he needed admission to hospital for pneumonia, and in September, 1960, reported that he had effort dyspnoea, that he had lost weight, and that he had frequent bouts of indigestion.

CASE 7.-J. C. M., a coal-miner aged 33 years, had suffered for four years from pain in the right side of the chest, relieved by lying down. Ten years before he had been crushed by a fall of coal at work, and remained in hospital for 12 months with a fracture of the skull and a fracture of the lumbar spine with paraplegia. He was admitted to Sully Hospital on December 13, 1950, following an attack of dyspnoea and right-sided chest pain. Chest radiography and barium studies showed a loop of colon reaching up to the apex of the right pleural cavity (Fig. 6). His acute symptoms subsided and he refused further investigation and treatment. In November, 1958, he reported that he was working as a production inspector in an engineering factory, but that he suffered from effort dyspnoea and from frequent bouts of dyspepsia.

CASE 8.-D. T., a coal-miner aged 55 years, was crushed beneath a slowly descending pit cage. His trunk was acutely flexed, and later he was found to have a fracture of the base of the skull, fracture dislocation of the third and fourth lumbar vertebrae with paraplegia, and diastasis of the pubic symphysis. His cerebral condition improved by the next day, but he became cyanosed and dyspnoeic. The mediastinum was displaced to the right, the left side of the chest was dull to percussion, and breath sounds were absent. There were no bowel sounds in the chest. There was a marked difference between the chest radiograph taken on the day of injury (Fig. 7) and that of the following day (Fig. 8). Because of his condition films could not be taken in the erect position, and it was impossible to distinguish between visceral herniation through the diaphragm and haemothorax.

At left thoracotomy on November 18, 1955, a large anterior diaphragmatic tear was found. Most of the stomach had herniated together with some of the small bowel, transverse colon, and omentum. The stomach was tightly constricted at the defect but was viable; the herniated portion was tensely distended with much fluid and a little gas. The viscera were returned to the abdomen and the defect sutured. He made a good recovery from the thoracotomy and was
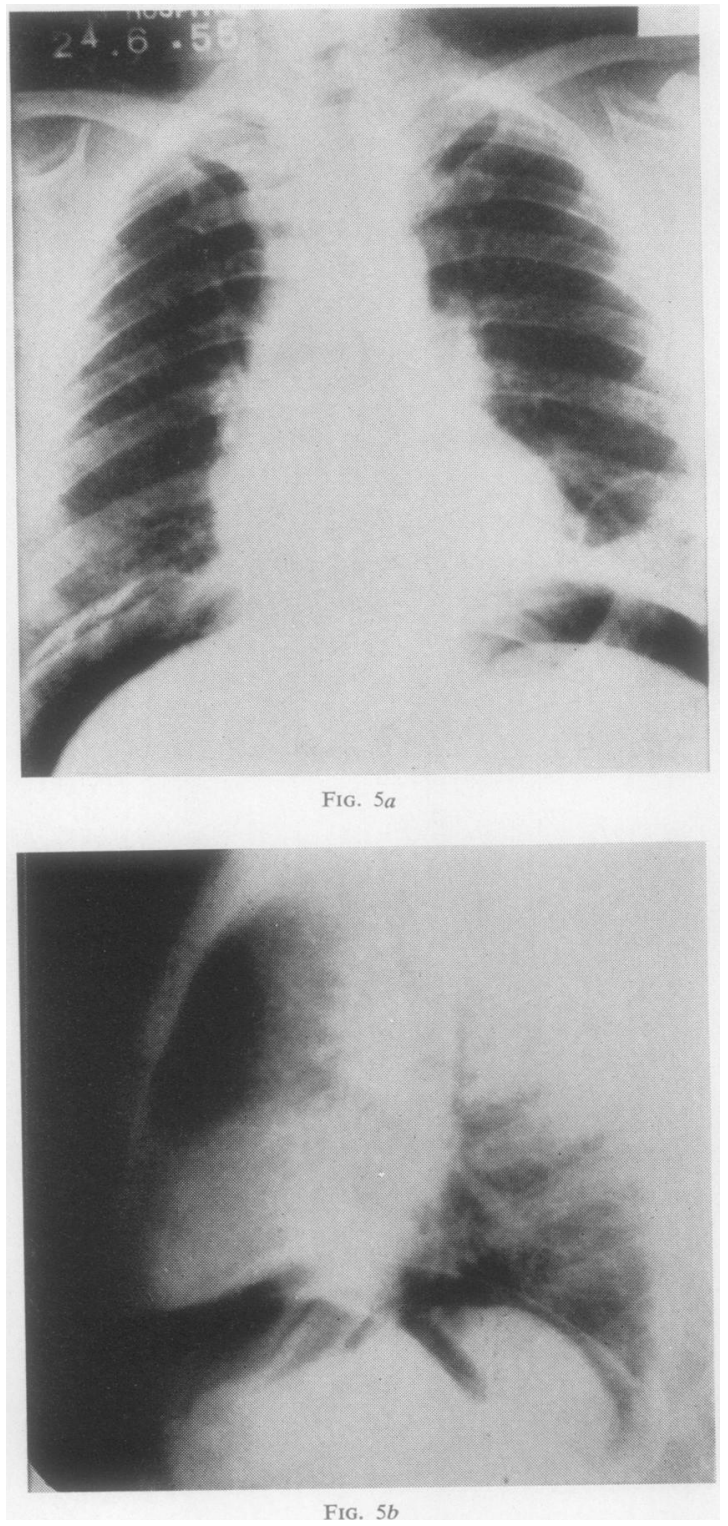

FIG. 5a and b.-Case 6: Postero-anterior and left lateral radiographs of chest after induction of artificial pneumoperitoneum. Some air has entered the hernia, but there is no pneumothorax. In the lateral film gastric rugae can be seen passing up into the hernia. The spleen is well shown. 


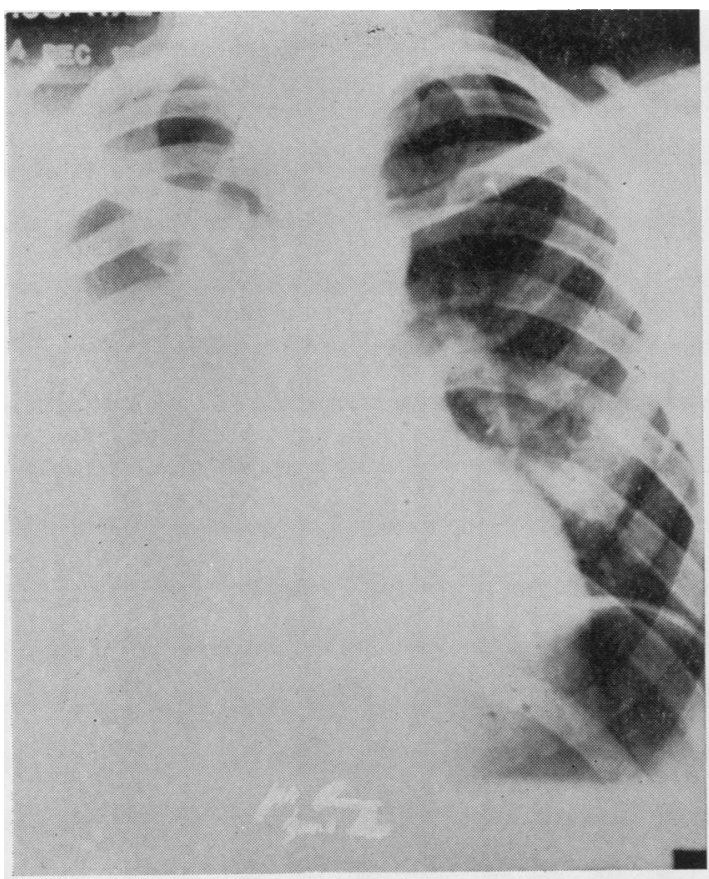

FiG. $6 a$

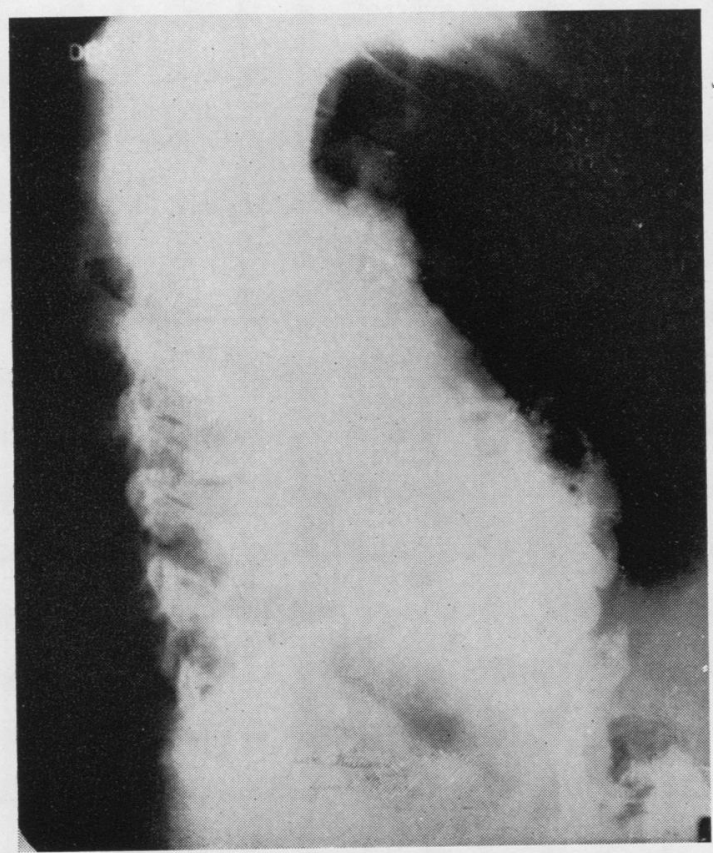

FIG. $6 b$

FIG. 6.-Case $7: a$, Postero-anterior radiograph of chest showing large size of traumatic hernia of right hemidiaphragm. $b$, Right lateral radiograph of chest during " follow-through" of barium meal examination. Contrast agent has only partially filled the herniated portion of colon which extends to the apex of the chest.

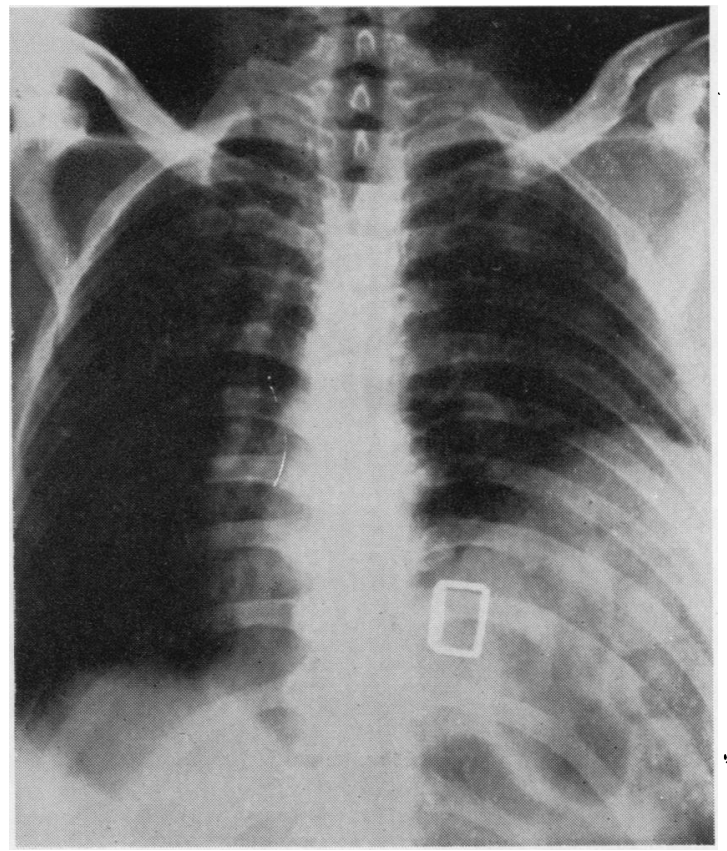

FIG. 7.-Case 8: Postero-anterior radiograph of chest on day of injury showing abnormal left diaphragm and a little mediastinal displacement to the right.

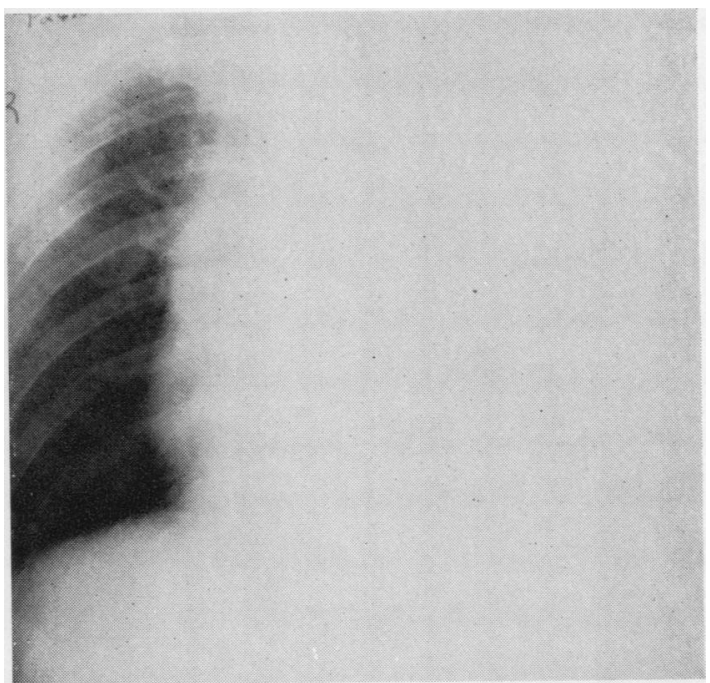

FIG. 8.-Case 8: Antero-posterior radiograph of chest taken on day following injury with the patient recumbent. There is a little clarity in the middle of the left-sided opacity. This was seen at operation to be due to the stomach being distended with fluid and gas. No fluid level was demonstrated because the patient's condition precluded taking an erect film. 

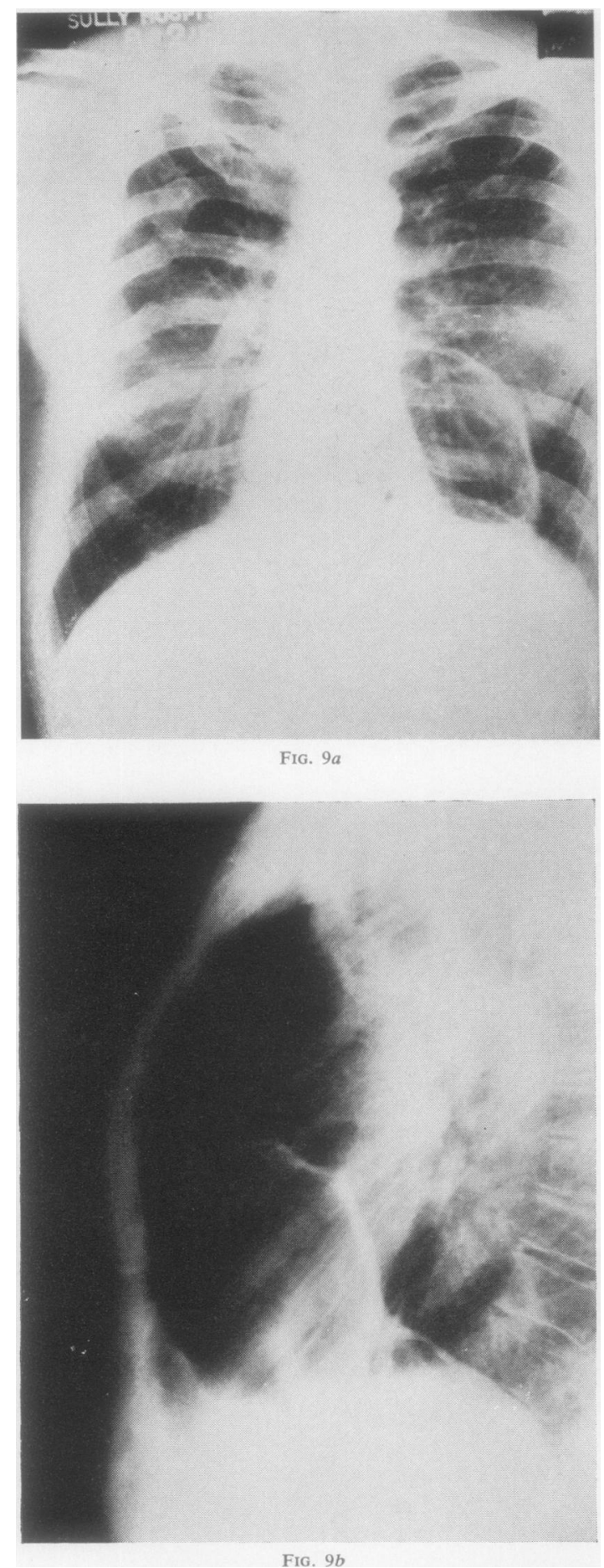

Fio. $9 a$ and $b$. -Case 9: Postero-anterior and left lateral radiographs of chest showing traumatic hernia of left hemidiaphragm. Barium meal showed that the herniated viscus was part of the stomach. The right-sided rib fractures and cross-union are well shown. soon able to co-operate in the treatment of his other serious injuries. In January, 1961, he was walking with the aid of a calliper. He reported that he had no dyspepsia.

CASE 9.-W. H., a coal-miner aged 58 years, had been crushed in 1944 between the pit roof and a truck on which he was travelling. He became very ill, needed transfusion, and recovery was slow. Four years later he began to become increasingly short of breath. Ten years after the accident he began to suffer from epigastric pain after food, relieved by lying down, and 16 months later consulted his doctor. His chest movements were poor and he became short of breath after walking 50 yards on the flat. Radiography showed part of the stomach in a left-sided hernia (Fig. 9). At left thoracotomy on March 9, 1957, a large central defect was found, without a sac. It extended back from the phrenic nerve, with its medial margin near the attachment of the pericardium, nearly to the oesophageal hiatus; laterally it extended into the muscular part of the diaphragm. The herniated parts of the stomach, transverse colon, omentum, and left lobe of the liver were returned to the abdomen. The defect could not be completely closed by suture and was reinforced with a free graft of parietal tissue as described below. He appeared to make a good immediate recovery, but died suddenly on the nineteenth post-operative day. At necropsy the diaphragmatic repair was shown to be sound. The lungs were emphysematous and there was hypostatic pneumonia of the lower lobe of each lung. The suddenness of his death was unexplained.

CASE 10.-T. B., a coal-miner aged 63 years, had a haemoptysis five months before admission. He had been wounded in the right side of the chest in 1917 and had had an operation on the chest wall. Radiography showed an anterior opacity above the right diaphragm; fluoroscopy showed poor movements. Bronchoscopy was normal; bronchography showed mild right lower lobe bronchiectasis.

At right thoracotomy on July 28,1954 , the lung was universally adherent. There was an anterior defect in the diaphragm, three inches in its longest diameter, forming the margins of a firm fibrous sac. Part of the right lobe of the liver projected into the sac but was not adherent to it. The sac was excised and the defect sutured. He made a good recovery. In April, 1957, he was well; radiologically the diaphragmatic repair was sound and the lung fields clear. He died at home in December, 1957, after an illness in which he lost weight and had a copious haematemesis.

CASE 11.-D. D., a coal-miner aged 53 years, was injured in a motor accident in 1951, when he was treated for fractured right ribs and a fractured pelvis. From that time he complained of dyspnoea, and was sent for investigation following mass miniature radiography at work. There was a rounded opacity above the right diaphragm (Fig. 10). Barium studies were normal. Induction of a pneumoperitoneum resulted in a small pneumothorax. At right thoracotomy on 

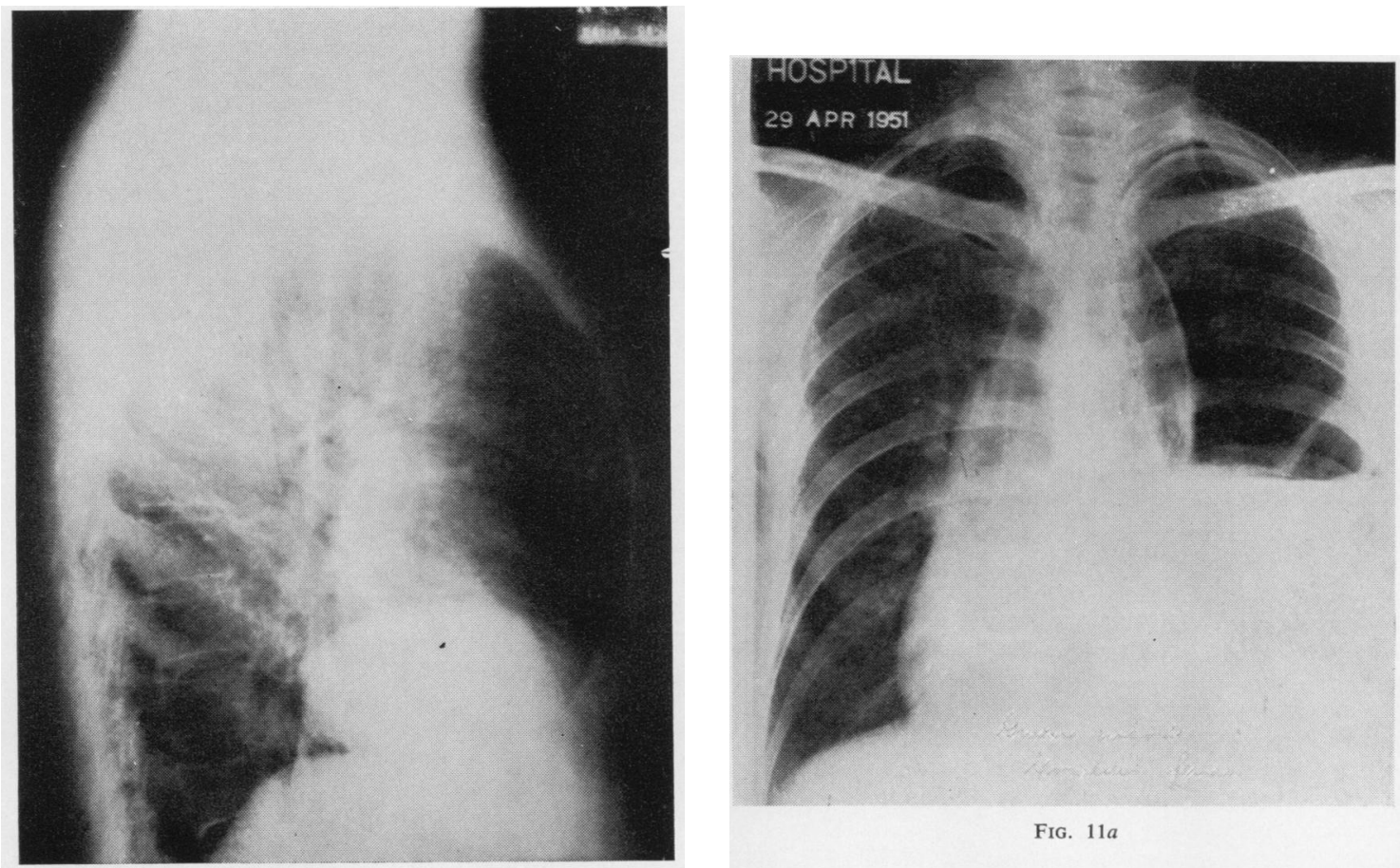

Fig. $10 a$

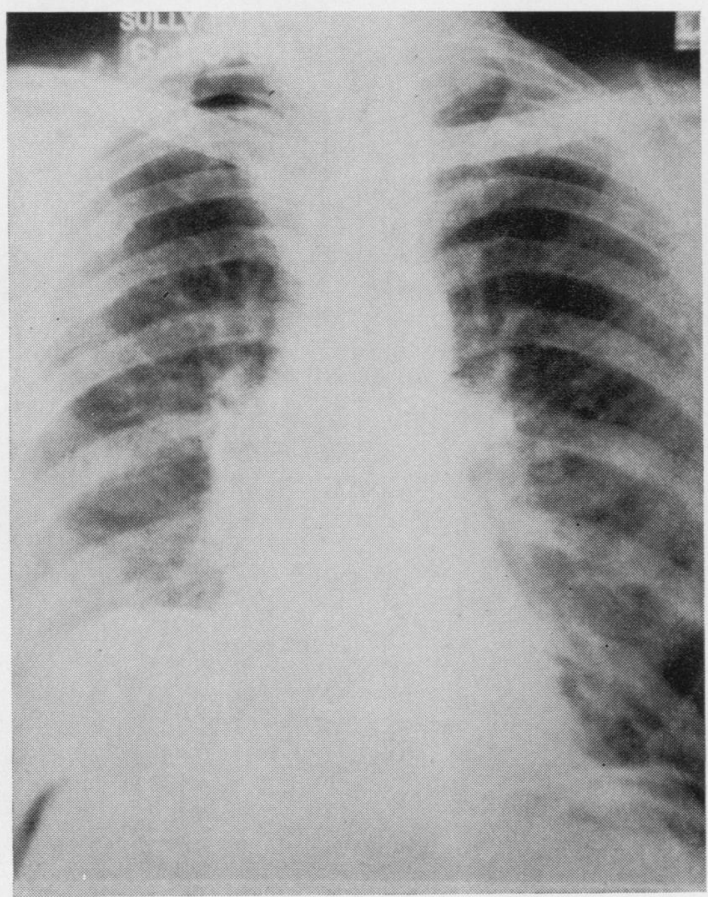

FIG. $10 b$

Fig. 10.-Case 12: $a$, Right lateral radiograph of chest showing herniation of part of the liver through the right hemidiaphragm. $b$, Postero-anterior radiograph of chest after induction of pneumoperitoneum. A shallow pneumothorax could be seen in the original film. There is a healed fracture of the right fifth rib.

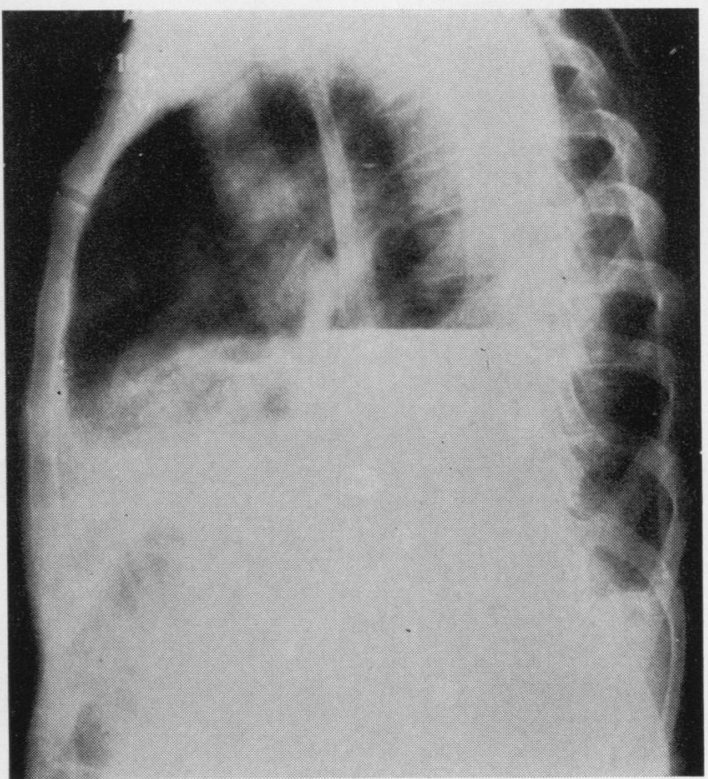

FIG. $11 b$

Fig. $11 a$ and $b$-C Case 13: Postero-anterior and left lateral radiographs showing distended stomach, small intestine, and colon in the left side of the chest. The left lung is compressed and a pneumothor $a x$ is present. 
October 13, 1954, a "mushroom" of liver projected through a defect in the anterior part of the diaphragm; there was no sac. The defect was enlarged a little to allow the liver to be reduced, and was sutured in two layers. Recovery was uneventful. In February, 1961, he reported that he was well and working as a boilerman on a housing estate.

CASE 12.-O. D., a coal-miner aged 46 years, had slipped from his support while operating a drill at shoulder height and had fallen heavily backwards against a pile of coal while at work in 1938. Two hours later he felt faint for a few minutes, but was able to return to work the next day. A few days later he became ill with bronchitis and remained at home for nine weeks. Thereafter he was in a sanatorium for 14 weeks complaining of cough, pain in the left chest, and night sweats. Sputum examination was negative for tubercle bacilli. In the succeeding years he suffered from time to time from pain in the left side of the chest and shortness of breath. Sixteen years after injury radiography showed a high left diaphragm which moved paradoxically. Induction of a pneumoperitoneum was not helpful, but diaphragmatic herniation was diagnosed without contrast radiography.

At left thoracotomy on January 26,1955 , the lung was adherent to the diaphragm, and there was a hernia with a sac. Its neck was wide and its anterior margin was formed by a prominent ridge of muscle near the ribs. It contained the spleen and most of the stomach. Most of the sac was excised and the defect sutured with overlapping. Histological examination showed the sac to be entirely fibrous. Though bronchospirometry before and after operation showed little difference, the patient noticed great improvement in his breathing. In February, 1961, he was well and working, and the diaphragmatic repair appeared sound radiologically.

CASE 13.-C. L., a coal-miner aged 51 years, had been injured at work 17 years previously when a fall of rock fractured the left tibia and fibula and two ribs on the left side. He was treated in hospital for two weeks, and was off work for six months.

For five years after the accident he suffered from attacks of colicky substernal and epigastric pain lasting about 10 minutes and occurring about once a month. He remained well for the next 11 years; but six months before admission to hospital he developed right lower abdominal pain, lassitude, and loss of appetite. Two weeks before admission he experienced pain in the left upper chest with an unproductive cough; one week before admission he suddenly became short of breath and collapsed while out walking, and remained in bed at home with fever. On examination the chest moved poorly, the trachea was displaced to the right, the left chest was hyperresonant and breath sounds were absent on this side. Bowel sounds could be heard all over the left chest. There was a palpable lump in the right iliac fossa. There was intermittent fever up to $102^{\circ} \mathrm{F}$. and the haemoglobin was $64 \%$. Chest radiography (Fig. 11) showed the stomach, together with colon and small bowel, occupying the left side of the chest. There was a small left-sided pneumothorax, and the lateral film showed a little gas under the left diaphragm.

Diagnostic aspiration at the base of the left chest was negative. He was given two tranfusions of packed red cells. The fever was not influenced by antibiotics. Air was aspirated from the left pleura and later an apical drain inserted. Three weeks after admission his condition deteriorated rapidly: he complained of abdominal pain, and was tender and rigid over the whole abdomen. He developed peripheral circulatory failure and died.

At necropsy there was a defect 6 in. in diameter in the dome of the left hemidiaphragm. There was no hernial sac; the oesophago-gastric junction was normally placed, but most of the stomach lay in the left pleural cavity together with much of the transverse colon and small bowel. There were no adhesions, but the viscera were covered with a small amount of fibrinous exudate. There was a carcinoma of the caecum with gross invasion of mesenteric and para-aortic lymph nodes. There was an acute ulcer of the anterior wall of the first part of the duodenum which had perforated causing generalized peritonitis.

It was concluded that the abdominal symptoms he had experienced in the last six months of his life were due to the caecal carcinoma. The acute episode three weeks before admission was attributed to leakage from the duodenal ulcer; the pneumothorax was explained by the passage of gas into the chest through the diaphragmatic defect, and the fever by the peritoneal and pleural exudates.

CASE 14.-S. J., a housewife aged 56 years, had been treated in hospital after an air-raid 17 years previously when the house in which she was living collapsed and she had been buried up to her shoulders in debris. Her vision was impaired for three weeks, but she was able to go home free from symptoms at the end of that time. Though four months pregnant at the time she later had a normal delivery, though her child only survived three weeks.

After this she continued to live a normal life, giving birth to healthy children in 1944 and 1947. She had noticed increasing shortness of breath in the six years before her admission to hospital. She was admitted to hospital following an acute episode in which she experienced numbness of the back of the head and arms and weakness of both arms; the attack rapidly subsided, leaving no residual signs. She said that she became short of breath when climbing stairs or walking fast, and that she could not lie on her right side because of difficulty in breathing. Taking large meals or copious drinks made her short of breath, but she had no dyspepsia. She was an obese woman; the blood pressure was $180 / 80 \mathrm{~mm}$. $\mathrm{Hg}$; at the base of the left chest there was dullness to percussion and poor air entry; bowel sounds could be heard all over the left side of the chest. Chest radiography (Fig. 12) showed a hernia through the left hemidiaphragm with much of the stomach, small 


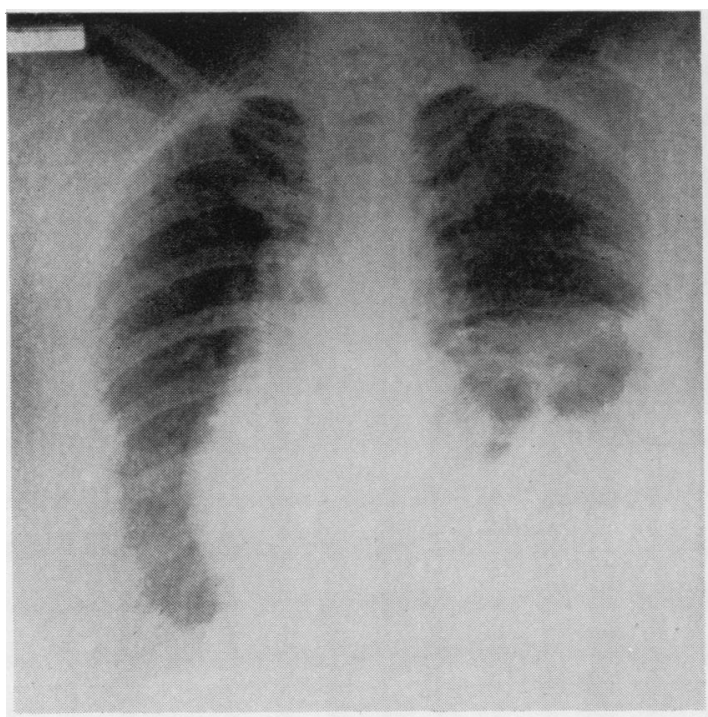

FIG. $12 a$

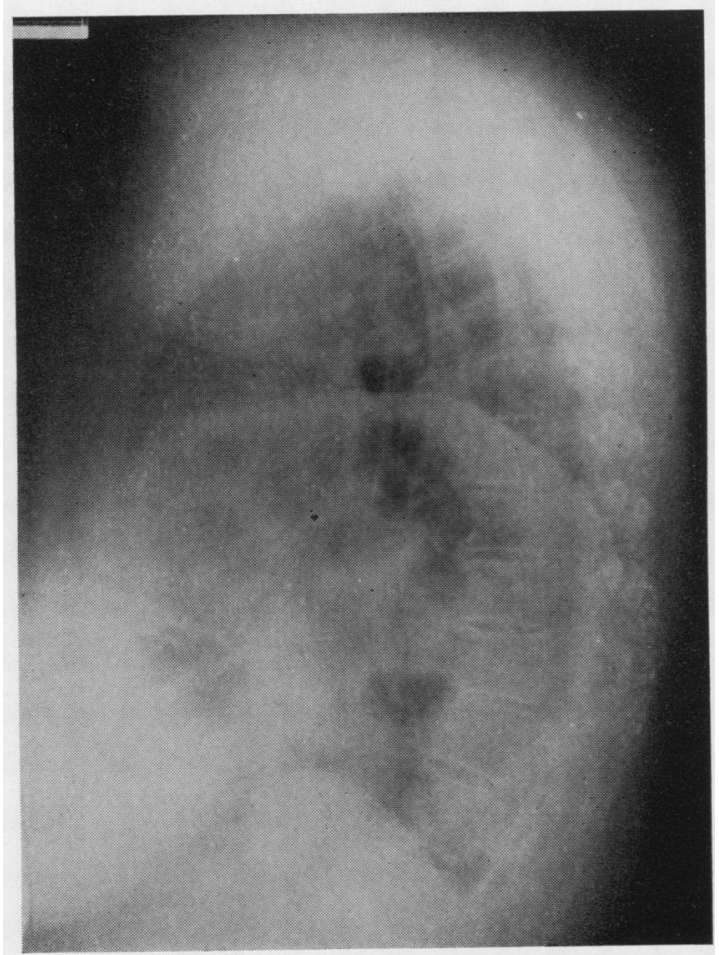

FIG. $12 b$

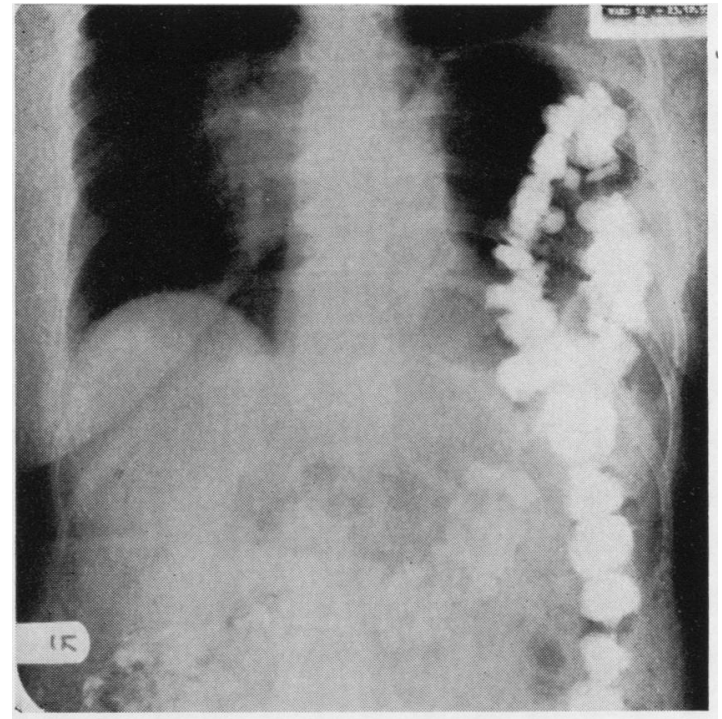

FIG. $12 c$

Fig. 12.-Case 14: $a$ and $b$, Postero-anterior and left lateral radiographs of chest showing herniation of stomach and colon through the left hemidiaphragm. There is spinal osteoarthritis, but no rib fractures were seen. $c$, The herniated colon shown by contrast radiography.

bowel, and colon in the chest. These findings were confirmed by contrast radiography.

This patient is now being treated for obesity, and is awaiting operation for the hernia.

CASE 15.-H. J., a coal-miner aged 57 years, had been crushed between two coal trucks 16 years previously and was admitted to hospital where his chest was strapped. After this accident he suffered from substernal pain after meals, and 12 years before admission, while being investigated elsewhere by barium meal, a left-sided diaphragmatic hernia was demonstrated. Ten years before admission he developed a persistent and productive cough; two years before admission he had a disabling attack of left-sided chest pain, and from that time onwards complained of occasional dysphagia, regurgitation, and substernal pain related to effort.

On admission he had a moderate kyphoscoliosis and his chest moved poorly. His maximum voluntary ventilation was 32 litres/minute. Chest radiography (Fig. 13) confirmed the presence of a hernia through the left hemidiaphragm; a barium meal examination did not reveal any gastric herniation or demonstrate oesophageal reflux. Oesophagoscopy showed no abnormality. Electrocardiography indicated ischaemic heart disease.

The herniation was thought to involve the liver or spleen only, and as his symptoms were mainly those of cardiac ischaemia and oesophageal reflux, and because of his poor cardiac and respiratory function, operation was not advised. 

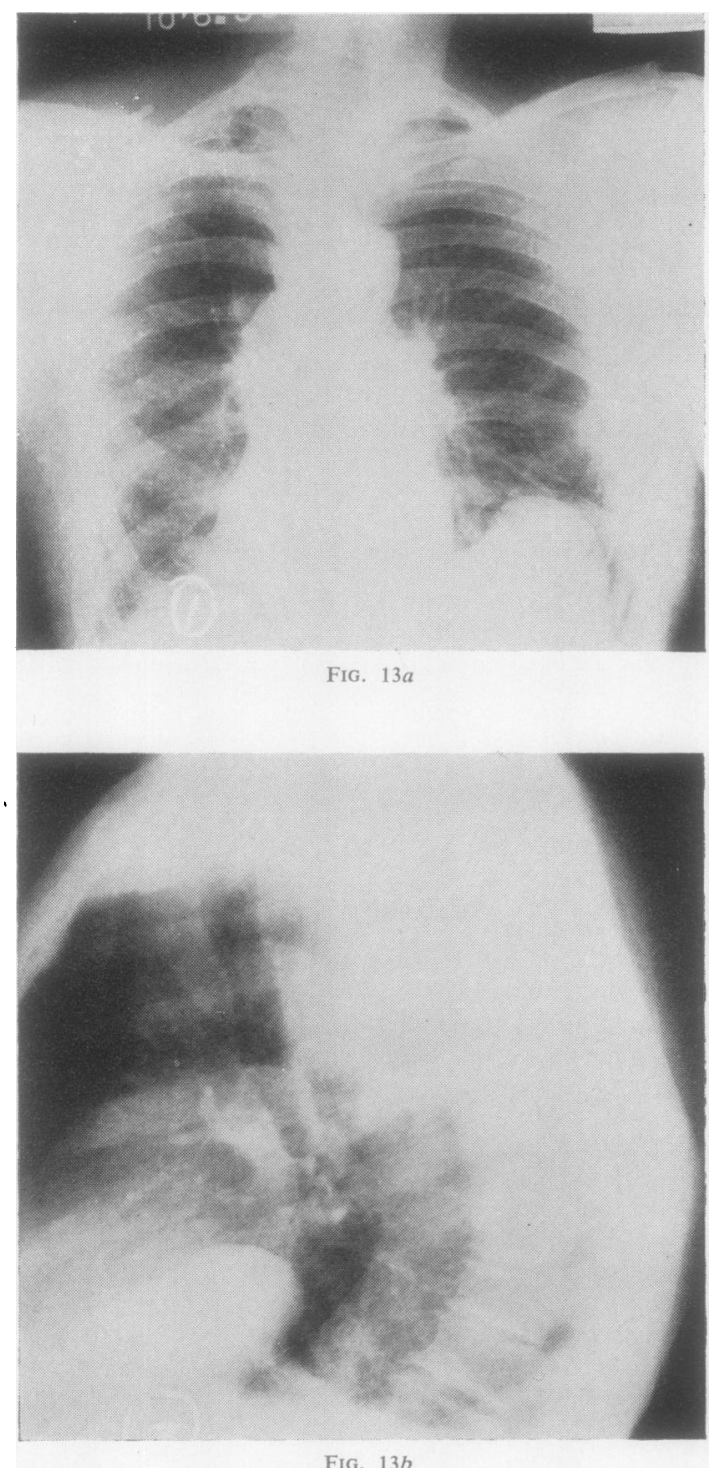

Fig. $13 a$ and $b .-$ Case 15: Postero-anterior and left lateral radiographs of chest showing herniation of a solid viscus (probably spleen) through left hemidiaphragm. There are healed fractures of the seventh and eighth right ribs. (No operation was performed and proof of herniation is lacking in this case. It is admitted that a similar appearance may be seen in cases where no hernia exists.)
He was treated with antacids with much improvement, but reported in February, 1961, that he was still troubled by dyspnoea and pain in the left side of the chest.

\section{DiAgnosis}

The diagnosis of traumatic diaphragmatic hernia is rarely obvious, and in practice is made either soon after injury or following a long interval during which symptoms are slight or absent.

EARLY Diagnosis.-In penetrating injuries diaphragmatic injury frequently follows a small external wound. Diaphragmatic rupture is always

TABLE II

HERNIAE DUE TO PENETRATING INJURY

\begin{tabular}{|c|c|c|c|c|}
\hline $\begin{array}{l}\text { Total number } \\
\text { Right sided } \\
\text { Left . . } \\
\text { Hernia diagnosed early } \\
\qquad,, \quad,, \quad \text { late }\end{array}$ & $\begin{array}{l}\cdots \\
\cdots \\
\cdots \\
\cdots\end{array}$ & $\begin{array}{l}\cdots \\
\cdots \\
\cdots \\
\cdots\end{array}$ & $\begin{array}{l}\cdots \\
\cdots \\
\cdots \\
\ldots\end{array}$ & $\begin{array}{c}4 \text { (all men) } \\
1 \\
3 \\
1 \\
3\end{array}$ \\
\hline
\end{tabular}

Average delay period in herniae diagnosed late-19 years Shortest-6 ,",

Average age at time of treatment -41,

TABLE III

HERNIAE DUE TO CRUSHING INJURY

\begin{tabular}{lcccc|c}
\hline Total number &. & $\ldots$ & $\ldots$ & $\ldots$ & 11 (10 men, 1 woman) \\
Right sided & $\ldots$ & $\ldots$ & $\ldots$ & $\ldots$ & 2 \\
Left \\
Hernia diagnosed early
\end{tabular}

Average delay period in herniae diagnosed late- $10 \frac{1}{2}$ years Shortest - 6 months

Average age at time of treatment Longest-17.1 years

a possibility where there has been crushing injury to the chest or abdomen, and its presence is not excluded by the absence of rib fractures (Evans and Simpson, 1950 ; present series, Cases 3, 7, 8, 11,12 , and 14). Radiography may be difficult due to the patient's poor condition and associated injuries, as it was in our Case 8. Sutherland (1958) stressed the danger of missing a visceral fluid level by radiography in the supine position, and the value of antero-posterior radiography in the lateral position in patients in poor general condition.

Evans and Simpson recorded distressing dyspnoea and cyanosis in two of their seven patients with herniae due to crushing. Dyspnoea was marked in Cases 3 and 8 of our series, but as it is a fact that miners suffering from pneumoconiosis and emphysema may become desperately ill from this cause following fracture of a few ribs only, the symptom is not of great diagnostic help. 
It has now become our practice to make a critical examination of the diaphragm in all cases of crush injury of the chest or of the abdomen.

Though not observed in our series, intestinal obstruction may give the first indication of diaphragmatic injury (Dugan and Samson, 1948 ; Meyer, 1950).

Late Diagnosis. - Diagnosis of traumatic diaphragmatic hernia may be made a long time after the injury that caused the tear in the diaphragm. It may be an " accidental" finding during mass surveys (Cases $1,6,11$, and 12), or during the investigation of coexisting respiratory disease (Cases 10 and 14). Often the diagnosis is made when investigating ill-defined abdominal symptoms (Cases 2, 7, 9, and 15). In Case 5 the patient had suffered from substernal pain after food from the time of his injury to his emergency treatment for haematemesis; while in Case 13 the complications of serious intestinal disease brought the hernia to light. In a patient treated by $\mathbf{R}$. $\mathbf{H}$. Gardiner there was a long interval without symptoms after wounding in the first world war. Acute obstruction of the colon developed $33 \frac{1}{2}$ years later, preceded only by a few months of mild premonitory symptoms (Probert, 1959).

In cases following penetrating wounds it is not uncommon for the symptoms to be attributed to malingering or hysteria for many years. The reason is that the initial hernia is small and escapes notice; the condition is wrongly diagnosed and the diagnosis persists. Diaphragmatic herniae tend to be ingravescent; they increase in size continuously and their later discovery may explain symptoms that have long been attributed to psychological causes. Tudor Edwards diagnosed one such case after 25 years (Barrett, 1959).

Diagnostic Difficulty Due to Phrenic PARALYSIS.- There is a danger of confusing acute, or transient, phrenic paralysis (such as commonly occurs in all sorts of war injuries of the chest) with diaphragmatic hernia. Although rare, this mistake has been reported by Barrett (1959). It may seem even stranger that phrenic paralysis should cause difficulty in cases treated after a long interval. In the following case, though phrenic paralysis was thought to be a very likely effect of the original injury, the diaphragmatic abnormality mimicked a hernia closely.

A man aged 44 years had received multiple injuries in a motor-cycle accident nine years previously. The cervical spine, right scapula, and right humerus had been fractured and the right brachial plexus severely damaged. His right arm was later amputated, but severe shoulder pain persisted. Five weeks before

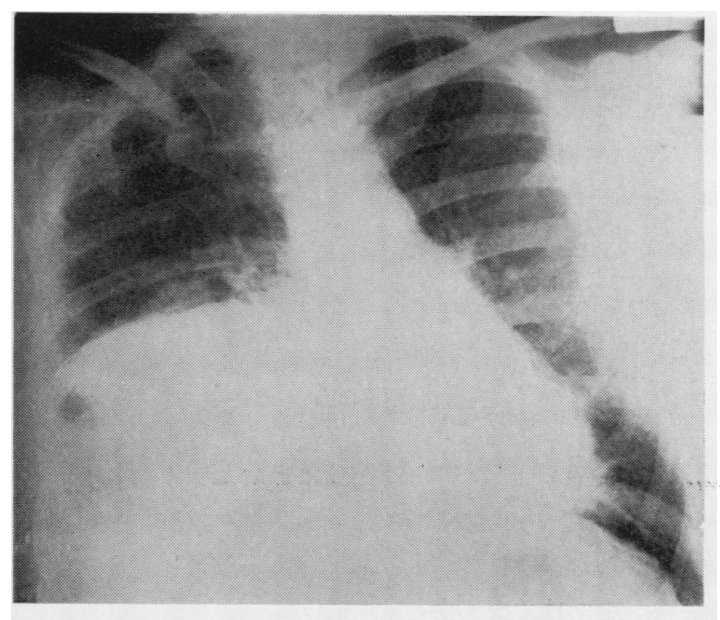

FIG. $14 a$

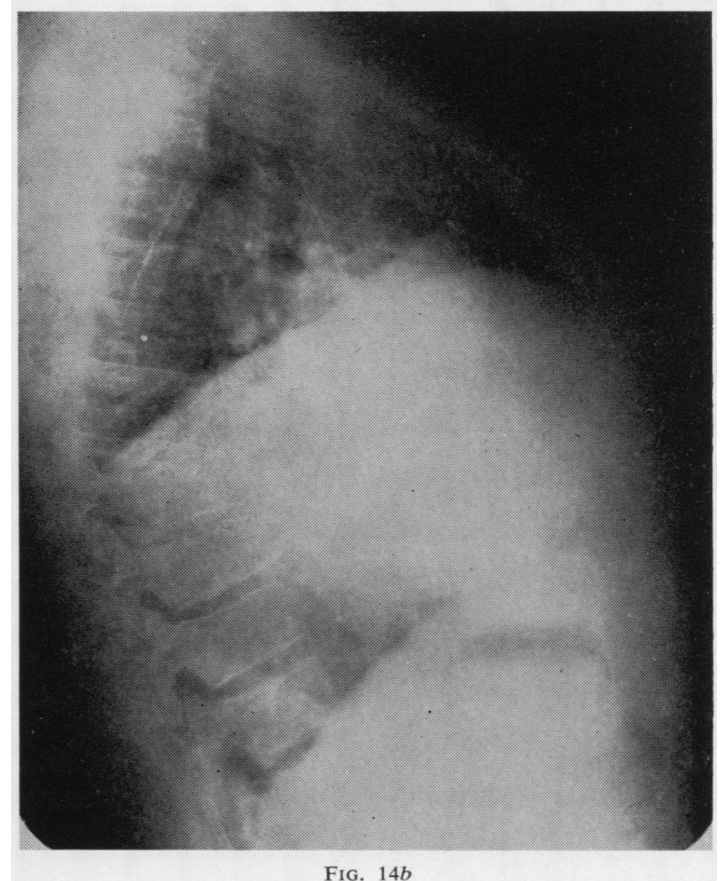

FIG. 14. $\rightarrow a$, Postero-anterior radiograph showing malunited fracture of clavicle. The right hemidiaphragm is high. There is a translucency corresponding to the hepatic flexure of the colon. $b$, Corresponding right lateral film. The opacity in the right lung was interpreted as an area of atelectasis. The appearance was thought to indicate a hernia; operation revealed a paralysed but intact diaphragm. 
admission he developed epigastric pain. Radiography suggested herniation through the right hemidiaphragm (Fig. 14), but at thoracotomy the diaphragm was found to be high and atrophic due to phrenic nerve injury, and there was no indication of localized injury to the diaphragm. The abnormality was treated by plication.

\section{A similar case was even more confusing.}
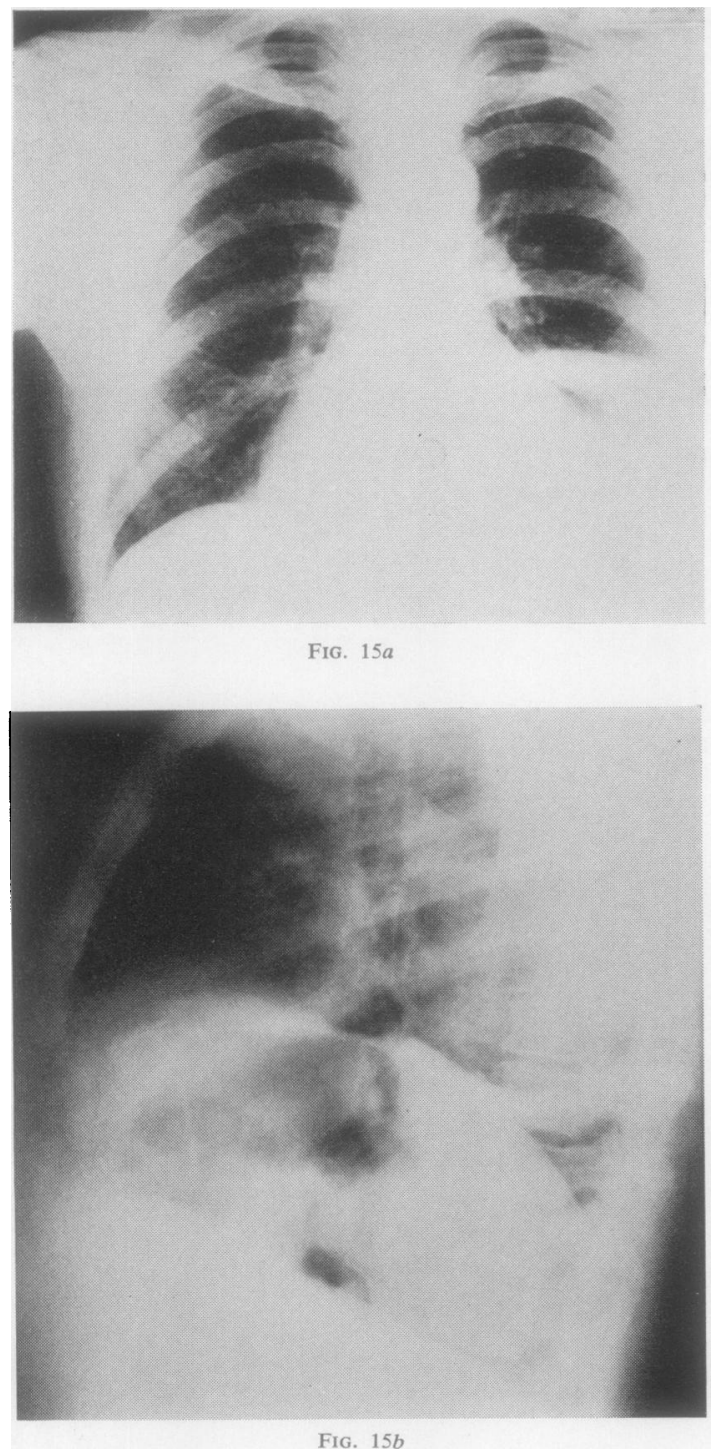

Fig. 15.- $a$, Postero-lateral radiograph of chest showing high left hemidiaphragm. $b$, Left lateral film. The stomach, colon, and spleen are shown; the opacities in the left lung were interpreted as areas of atelectasis. The irregularity anteriorly was thought to indicate herniation; operation revealed a paralysed but intact diaphragm.
A coal-miner aged 46 years had been crushed between two trucks and had been off work for 16 weeks in 1956. Two years later he noticed increasing shortness of breath, and two years later still he complained of pain in the left side of the chest. Radiography showed the left hemidiaphragm to be high with paradoxical movement (Fig. 15), but herniation was considered likely. At left thoracotomy there was no defect in the diaphragm, which was thin and atrophic. A localized area of irregularity in the phrenic nerve suggested a probable site of former injury.

\section{The Hernial Contents}

The stomach, small intestine, colon, and spleen call for no further comment. Rarely the kidney may enter a hernia due to penetrating injury (Barrett, 1945 ; Paul, Uragoda, and Jayewardene, 1960). The liver may pass as a whole into the right chest (Case 7), but it is not generally appreciated that part of the liver can protrude like a mushroom through a defect (Case 10). This is because the organ is not, as many imagine, a solid, wooden sort of structure whose shape is fixed, but is capable of being moulded by stresses around it. Part of the liver may occupy a left-sided hernia as it probably did in Case 15. We have also seen at operation a "mushroom" of the left lobe of the liver occupying a congenital hernia through the anterior part of the left diaphragm. (Sully Hospital Case No. 02670, to be reported.)

\section{ACCOMPANYING INJURIES}

Other injuries resulting from the original trauma are often serious and are shown in Table IV. Barrett has reported the case of a miner in whom rupture of the diaphragm without fracture of ribs was associated with a hyperextension fracture of the thoracic spine and a chylothorax. In the experience of many surgeons the patients most likely to suffer from rupture due to increased

TABLE IV ACCOMPANYING INJURIES

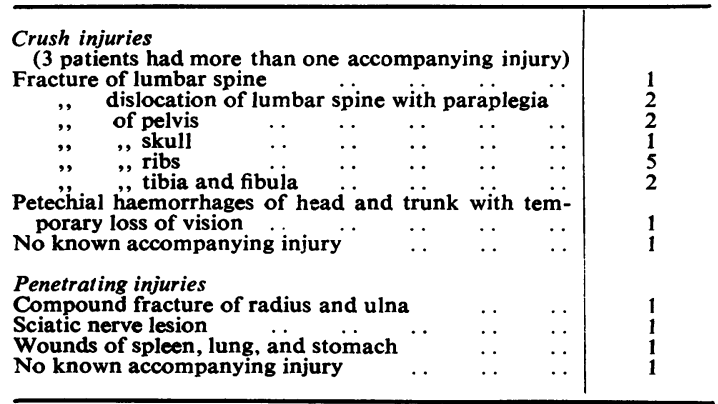


intra-abdominal pressure are infants and young children whose abdomens have been run over. Rather surprisingly there have been no herniae due to this cause in our series. In Evans and Simpson's series five out of seven herniae due to non-penetrating injury followed accidents of this kind; four of these patients had fractures of the pelvis, none had fractured ribs, and all escaped visceral injury. Abdominal visceral injuries were few among our patients, but their menace was impressed on us by the following case (not one of this series):

A coal-miner aged 44 years was crushed at work. Three days later his condition rapidly deteriorated and left thoracotomy was needed for haemothorax due to two ruptured intercostal arteries. Exploration showed a tear $1 \mathrm{in}$. long in the muscular part of the diaphragm in the line of its fibres but not involving its whole thickness. Extending this incision into the peritoneal cavity revealed a thin film of blood due to an unsuspected rupture of the spleen. Splenectomy was performed.

In two herniae due to crushing (Cases 3 and 14) there were widespread petechial haemorrhages at the time of injury. Though not rare in our experience of crushing injuries of the chest, this phenomenon is transient and seems unimportant.

Dr. Roger Seal, pathologist to Sully Hospital, has recently drawn our attention to an association of injuries in two further cases of diaphragmatic rupture (not included in the above analysis).

A car driver and his passenger were killed instantly in an accident. Necropsy on each of them showed similar findings: a tear through the left hemidiaphragm parallel with the pericardial attachment, accompanied by complete transection of the aorta at the beginning of its descending portion.

\section{The Mechanism of Diaphragmatic Tearing in CRUSHING INJURIES}

Only one of our cases followed a car accident, one was the result of an air raid, and the remaining nine followed accidents at work. In many of these the crushing mechanism was slow, and it is possible that the diaphragm became more liable to rupture as a result of violent respiratory efforts during the period of compression.

In depicting the mechanism of rupture Desforges et al. (1957) show a tear in the cupola due to the abdominal viscera being compressed against the diaphragm. If such compression were the most important feature in these accidents it would be reasonable to expect visceral injury to occur more often than it does. It is noteworthy that Carlson, Diveley, Gobbel, and Daniel (1958) in a review of the English language literature on traumatic diaphragmatic hernia from 1946 to 1957 found visceral injury in 22 of 99 patients, but mining accidents accounted for only five of the entire series. Furthermore, in our Cases 3, 8, and 9 each defect lay close to the chest wall, and the narrow rim of tissue at the periphery in each case suggested avulsion of an active muscle rather than bursting of a passive sheet of tissue. Some light may be thrown on this matter by the possibility of rupture of the diaphragm during labour. Though rare, such a case has been described by Barrett (1959). After a prolonged labour resulting in the birth of twins, severe vomiting, at first misdiagnosed as " toxaemia," led to the diagnosis of strangulation of bowel herniated through a recent diaphragmatic tear. Recovery following operation was complete.

Another possible mechanism considered by Desforges and his collaborators was that forces compressing the chest from opposite directions could rupture the diaphragm like the membrane of a drum. Under these conditions the tear was expected to occur in the line of compression and again to be centrally placed. It is difficult to reconcile this concept with the arched shape of the diaphragm and its laxity. Furthermore, in Cases 3, 8, and 9, where we have evidence from the clinical history that the chest was compressed this way, the tears were peripheral.

We are unable to explain the mechanisms involved, but we think that forced respiratory movements of the diaphragm during crushing are important.

\section{Partial Tears}

In Case 3, in addition to a large defect anteriorly in the diaphragm, two separate peripheral tears of muscle and pleura were found under which the peritoneum was intact.

It has long been realized that the difference between thoracic and abdominal pressures can cause delayed herniation by acting on a thin diaphragmatic scar or an omentum-plugged gap. If this mechanism acted upon an incomplete tear a hernial sac might be expected. Hollander and Dugan (1955) found a sac proved by microscopy in one of their cases of traumatic diaphragmatic hernia, and in another demonstrated the herniated liver covered by stretched diaphragmatic pleura.

\section{The Presence of a Hernial Sac}

Hernial sacs were found in two of our patients. In one (Case 10), where the hernia resulted from penetrating injury, there was a thin fibrous sac, and microscopy showed collagenous tissue with no muscle fibres. In the other patient (Case 12), 
where the hernia resulted from a crushing injury, the central part of the diaphragm was seen at operation to be replaced by a thin layer of tissue ; microscopically this was shown to be collagenous and muscle fibres were absent.

Hughes and others (1948) found sacs in only two of their 28 cases, but stated that " there was often a membrane covering a part of the herniated structure, but it was not complete." This observation suggests that the membrane is a newly formed structure. The organization of blood and pleural exudate on the surface of herniated viscera could result in the formation of a fibrous or collagenous sac, and the finding of sacs in herniae due to penetrating injury suggests that they can be formed in this way even when the initial injury involves all layers of the diaphragm. An explanation of sac formation in penetrating injuries has been advanced by Barrett (1945). Within a few hours of injury a tiny knuckle of omentum insinuates itself through a hole, particularly if the hole is small. The resulting mushroom of omentum gradually increases in size and becomes invaginated by gut. The limiting layer of omentum forms a "false sac" as opposed to a " true sac" formed by peritoneum.

\section{RESPIRATORY HAZARDS}

Of the cases diagnosed early respiratory embarrassment was present in Case 8 and was a prominent feature in Case 3 . Of the cases diagnosed late dyspnoea was complained of by five patients (Cases 9, 11, 12, 14, and 15), in one of whom (Case 9) it was severe. In this patient the maximum ventilatory volume was only 40 litres/minute, but bronchospirometry showed no differential loss of lung function. The overall loss of function was attributed to pneumoconiosis and emphysema, and this contributed to the fatal result in his case.

Three patients (Cases 1, 12, and 15) had been under review from time to time by the Pneumoconiosis Panel of the Ministry of Labour and National Insurance. It is significant that though the diagnosis of diaphragmatic injury was made late in Case 12 the patient had had a severe chest infection soon after his original injury. We believe that this was the result of retention of bronchial secretions in a patient whose injuries and impaired lung function made coughing difficult. We have already commented on the danger of chest injury in patients with impaired lung function. In them excessive analgesia can be hazardous, and we are convinced of the need to limit analgesics to a minimum. Doses tolerated by patients with normal lung function may be disastrous in those with poor lung function. These patients must not be allowed to lie drowsy and immobile, but with the chest firmly supported must be vigorously encouraged to cough up all retained bronchial secretions.

\section{SElection OF TIME fOR OpERATION}

In those cases diagnosed early Edwards (1943) and Tubbs (1955) advise delaying operation till the patient has recovered sufficiently from his other injuries. This principle was followed in Case 3, when it was three days before the patient was fit for operation; fortunately the herniated bowel was amply viable. On the other hand, Dugan and Samson (1948) and Bugden et al. (1955) recommend early operation to prevent intestinal obstruction, while Sutherland (1958) in his series of 10 cases of indirect traumatic rupture of the diaphragm found two examples of strangulation of the stomach. In both of them gross distension of the body of the stomach had drawn the left gastric vessels tightly against the intact muscular margin of the oesophageal hiatus which was not involved in a neighbouring tear. In our Case 8 at an operation not lightly undertaken because of the serious spinal injury, the stomach was found tightly constricted by the defect in the diaphragm on the day after the accident.

\section{OPERATION}

The approach was by thoracotomy in all our patients, but laparotomy was added in Case 4. Separation of adhesions in late cases and repair of the diaphragmatic defect is easier by the thoracic route. Apart from the main defect our experience suggests that an attempt should be made to repair any partial tears, treating them as weak spots liable to develop into herniae. An attempt was made in all our patients to approximate the edges of the main defect itself with a double layer of interrupted linen thread sutures. Difficulties were encountered when the defect lay close to the costal margin or extended beneath the attachment of the pericardium, and in these part of the repair was in one layer only. In one patient (Case 9) there was difficulty in repairing the diaphragm. The edges were brought together as far as possible, but a central gap remained. This was covered by a free graft of tissue from the chest wall as described below.

\section{A Method of Tissue Grafting}

At Sully Hospital grafts of muscle, fascia, and periosteum from the chest wall were formerly 


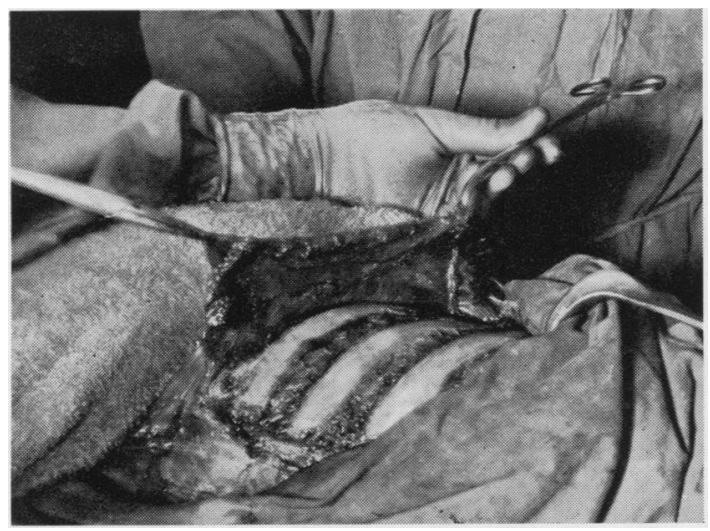

FIG. 16.-Photograph showing thickness of flap of tissue taken from chest wall. In this illustration the flap was used for reinforcing the roof of an osteoplastic thoracoplasty, but a similar flap can be used to repair other types of defect. The method of raising this flap is described in the text.

used to strengthen the roof of the refashioned thoracic cage in osteoplastic thoracoplasty, and are now used from time to time to repair costal defects after excision of tumours. The graft is taken from the outer aspect of the ribs most conveniently related to the defect. The diathermy needle is used to outline the extent of the graft, the base of which will remain attached to the lower border of a rib. The periosteum is raised from the whole outer surface of this rib with a curved rugine. With the freed periosteum and overlaying fascia held under moderate tension, another diathermy cut is made from within the periosteum through its attachment to the upper border of the rib into the muscle of the intercostal space. A layer of muscle, probably representing the greater part of the thickness of the external intercostal muscle, is dissected up until the lower margin of the rib above is reached. The periosteum of this rib is next incised along the extent of the graft and separated as in the case of the previous rib. The process is repeated until the graft is big enough for its purpose (Fig. 16), when it is turned upwards as a flap and sutured into position. In Case 9 this type of graft was used for diaphragmatic repair for the flrst time, but differed in that it was completely free.

\section{SUMMARY}

Fifteen cases of traumatic diaphragmatic hernia are reported, and associated injuries are mentioned.

The mechanism of diaphragmatic rupture in crush injuries and the significance of partial tears of the diaphragm are discussed.

The importance of respiratory disease in patients with crush injuries and the dangers of excessive analgesia are stressed.

A method of tissue grafting for diaphragmatic repair is described.

Our thanks are due to Dr. E. A: Danino, Dr. A. J. Thomas, Messrs. J. Elgood, J. F. E. Gillam, J. Russell Hughes, R. H. B. Mills, Melbourne Thomas, and E. Meurig Williams, who referred patients te this Centre; also to Dr. H. M. Foreman, physician superintendent, Dr. L. R. West, who performed respiratory function tests in some cases, and Dr. R. M. E. Seal, pathologist.

Our interest in this subject was kindled by Mr. Dillwyn Thomas, who was responsible for the treatment of all these patients; we thank him for his encouragement and advice.

Finally, we thank Miss Patricia Morse for secretarial help.

\section{REFERENCES}

Barrett, N. R. (1945). Brit. J. Surg., 32, 421.

— (1959). Personal communication.

Bryan, C. W. G. (1921). Brit. J. Surg., 9, 117

Bugden, W. F., Chu, P. T., and Delmonico, J. E. (1955). Ann. Surg., 142, 851 .

Carlson, R. I., Diveley, W. L., Gobbel, W. G., and Daniel, R. A. (1958). J. thorac. Surg., 36, 254.

Desforges, G., Strieder, J. W., Lynch, J. P., and Madoff, I. M. (1957) Ibid., 34, 779.

Dugan, D. J., and Samson, P. C. (1948). Ibid., 17, 771.

Edwards, A. T. (1943). Brit. J. Surg., 31, 74.

Edwards, A. T. (1943). Brit. J. Surg., 31, 74.

Hollander, A. G., and Dugan, D. J. (1955). J. thorac. Surg., 29, 357.

Hughes, F., Kay, E. B., Meade, R. H., Jr., Hudson, T. R., and Johnson, J. (1948). 'Ibid., 1\%, 99.

Mackey, W. A., and Bingham, D. L. C. (1945). Brit. J. Surg., 33. 135.

Meyer, H. W. (1950). J. thorac. Surg., 20, 235.

Morgan, C. N. (1945). Brit. J. Surg., 32, 337.

Paul, A. T. S., Uragoda, C. G., and Jayewardene, F. L. W. (1960)Ibid., 47, 395 .

Probert, W. R. (1959). Postgrad. med. J., 35, 153.

Sutherland, H. D'Arcy (1958). Ibid., 34, 210.

Tubbs, O. S. (1955). In Modern Operative Surgery, 4th ed, vol. 1, p. 431, ed. G. G. Turner and L. C. Rogers. Cassell, London. 